\title{
Probing surface interactions of underwater oleophobic polyelectrolyte multilayers
}

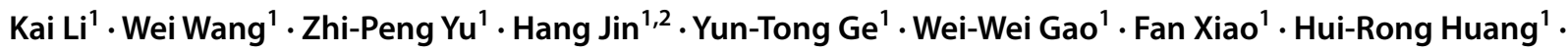 \\ Ze-Heng Peng ${ }^{1}$. Jing Gong ${ }^{1}$
}

Received: 16 May 2020 / Accepted: 3 July 2020 / Published online: 17 October 2020

(c) The Author(s) 2020

\begin{abstract}
In the present work, the interaction mechanism of specific polyelectrolyte multilayers (PEMs), fabricated by layer-by-layer deposition of polydiallyldimethylammonium chloride (PDDA) and poly(sodium 4-styrenesulfonate) (PSS), is studied using atomic force microscopy. The underwater oil-repellency of PSS-capped PEMs was further explored by measuring the interaction forces between tetradecane droplets and PEMs-coated silica substrates under various salinities. The force curves were analyzed following the Stokes-Reynolds-Young-Laplace theoretical model. Desirable consistency was achieved between the experimental and theoretical calculations at low $\mathrm{NaCl}$ concentrations $(0.1 \mathrm{mM}$ and $1 \mathrm{mM})$; however, underestimation of the attractive force was found as the $\mathrm{NaCl}$ concentration increases to moderate $(10 \mathrm{mM})$ and high $(100 \mathrm{mM})$ levels. Discrepancy analyses and incorporated features toward a reduced surface charge density were considered based on the previous findings of the orientation of anionic benzenesulfonate moieties (Liu et al. in Angew Chem Int Ed 54(16):4851-4856, 2015. https://doi.org/10.1002/anie.201411992). Short-range steric hindrance interactions were further introduced to simulate "brush" effect stemming from nanoscale surface roughness. It is demonstrated in our work that the PSS-capped PEMs remains a stable underwater lipophobicity against high salinity, which renders it potential application in surface wetting modification and anti-fouling.
\end{abstract}

Keywords Lipophobicity $\cdot$ Salinity $\cdot$ AFM $\cdot$ Polyelectrolyte multilayers $\cdot$ Surface roughness

\section{Introduction}

The wettability of solid surface has long been the spotlight of scientific research due to its substantial application in lubrication, waterproofing, antifouling, self-cleaning, and

Edited by Xiu-Qiu Peng

Electronic supplementary material The online version of this article (https://doi.org/10.1007/s12182-020-00521-2) contains supplementary material, which is available to authorized users.

Wei Wang

w.wang@cup.edu.cn

1 National Engineering Laboratory for Pipeline Safety, MOE Key Laboratory of Petroleum Engineering, Beijing Key Laboratory of Urban Oil and Gas Distribution Technology, China University of Petroleum, Beijing 102249, China

2 Key Laboratory of Environmental Protection Technology on Water Transport, Tianjin Research Institute for Water Transport Engineering, Tianjin 300456, China oil/water separation, in relation to industrial engineering applications such as in agricultural pesticide, electric power transmission, detergents, petroleum production, material modification, and biomedicine (Zheng et al. 2010; Guo et al. 2012; Song et al. 2019; Rostami et al. 2019; Ehsan et al. 2019; Luo et al. 2016; Sudha et al. 2019; Ahmadi et al. 2020). The fundamental theory of wetting is properly expressed by Young's equation (Young 1805), which describes the spontaneous wetting mechanism of a solid surface. Accordingly, solid surfaces with generally high free energy are modified using multiple materials to incorporate lipophobicity, hydrophobicity, or super-amphiphobicity under specific ambient conditions (Zhang et al. 2016a; Cao et al. 2008; Su et al. 2019; Rasitha et al. 2019).

The deposition of polyelectrolytes, as one of the prevalent methods for surface modification, has demonstrated superior advantages in the hydrophilization of charged surfaces due to the macromolecules' particular molecular configuration and strong electrostatically induced hydration (Chang et al. 2016). An extensive body of polyelectrolytes has 
been explored and reported to exhibit superior hydrophilicity upon contact with water (Decher and Schlenoff 2003; Kobayashi et al. 2012). Among all tested materials, the prominent surface hydrophilicity of polyelectrolyte multilayers (PEMs) fabricated by the layer-by-layer (LbL) electrostatic deposition of polydiallyldimethylammonium chloride (PDDA) and poly(sodium 4-styrenesulfonate) (PSS) is the most commonly investigated (Ghostine et al. 2013; Teng et al. 2008; Jurin et al. 2018; Zaibudeen and Philip 2018; Wang et al. 2013). Fundamental research on the surface wetting behaviors of (PDDA/PSS) ${ }_{n}$ PEMs (with " $n$ " denotes the number of bilayers) has demonstrated variation in terms of the underwater hydrophilicity of PDDA-capped (PDDA/ PSS $)_{3.5}$ PEMs and PSS-capped (PDDA/PSS $)_{4.0}$ PEMs, which depend on the molecular nature of the uncompensated ionic groups (Liu et al. 2015). In addition, PSS-capped (PDDA/ PSS $)_{4.0}$ PEMs was found to exhibit stable oil-repellency, although the reduced surface charge density stems from benzenesulfonate reorientation, which occurred upon tight contact with oil droplet (Jin et al. 2019). (Fig. S1 in Supporting Information).

Accordingly, effectual ways of revealing the wetting mechanism related to polyelectrolyte-modified surfaces involve a quantitative understanding of the interactions between objective liquids and polyelectrolyte surfaces. This study has been facilitated by the advent of the atomic force microscope (AFM) (Binnig et al. 1986), which permits the direct force measurement of interactions between homoand hetero-bodies within nano-Newton scale (Mate et al. 1989; Snyder et al. 1997; Aston and Berg 2002; Malotky and Chaudhury 2001). Moreover, the development of probe modification technique has promoted the exploration of interactions between deformable droplets/bubbles and solid surfaces (Dagastine et al. 2004a, 2006; Gunning et al. 2004; Vakarelski et al. 2010a; Balasuriya and Dagastine 2012; Tabor et al. 2011a, b; Wang et al. 2015; Jin et al. 2017; Shi et al. 2017). One interesting study applied the drop probe AFM technique to elucidate the intrinsic wetting mechanism of polyelectrolyte surfaces with varied hydrophobicity. The obtained results demonstrated a mutual correlated interaction between oil/water wettability of polyelectrolytes in specific surrounding liquid media (Shi et al. 2016). In addition, it is worth mentioning that molecular dynamics simulations have also been demonstrated to be an effective way in revealing the interaction mechanism of underwater oleophobicity of self-assembled monolayers (SAMs) with different head groups (Cheng et al. 2017; Liao et al. 2017).

In this work, we started by measuring the mutual forces of prepared (PDDA/PSS) ${ }_{4.0}$ PEMs in various $\mathrm{NaCl}$ solutions using AFM. Then, the acquired force curves were characterized by an electrical double-layer (EDL) force model to extract the surface potential of the PSS-capped PEMs. In addition, the AFM probe modification technique was utilized to explore the equilibrium and dynamic interactions between oil droplets and PEMs. A theoretical analysis of the experimental observation was performed based on the Stokes-Reynolds-Young-Laplace (SRYL) model (Chan et al. 2001, 2011a, b; Dagastine and White 2002; Dagastine et al. 2004b). The effect of salinity on the droplet-substrate interaction was discussed following the DLVO theory. By sequestering EDL with high salinity, the steric hindrance of PEMs was studied and characterized to provide understanding for the stable underwater lipophobicity of the studied PEMs against high salinity.

\section{Experiment and theoretical model}

\subsection{Materials}

Sodium chloride ( $\mathrm{NaCl}, \mathrm{BioXtra}, \geq 99.5 \%$ ), polydiallyldimethylammonium chloride (PDDA, $20 \mathrm{wt} \%$ in $\mathrm{H}_{2} \mathrm{O}$ ), poly(sodium 4-styrenesulfonate) (PSS), and 1-dodecanethiol were all purchased from Sigma-Aldrich and n-tetradecane ( $\geq 98 \%$ ) was purchased from Alfa. Deionized water with a resistance of $18.3 \mathrm{M} \Omega \cdot \mathrm{cm}$ was used in all preparation procedures. Monocrystalline silicon wafers coated with a homogeneous silica layer (approximately $300 \mathrm{~nm}$ thick) were cut into $1.2 \mathrm{~cm}^{2}$ squares and used as substrates. All preparations and measurements were performed at room temperature $\left(21 \pm 0.5^{\circ} \mathrm{C}\right)$.

\subsection{Preparation of PEMs substrates}

Initially, the silica substrates were pretreated with piranha solution to obtain a hydroxylated surface. Subsequently, the pretreated substrates were thoroughly rinsed with deionized water and dried under pure nitrogen gas. (PDDA/PSS) ${ }_{4.0}$ PEMs were produced following a LbL electrostatic deposition method previously described in the literature (Liu et al. 2015). This was conducted via the alternant immersion of silica substrates in aqueous solutions of PDDA $(1.0 \mathrm{mg} /$ $\mathrm{mL}$ and $1 \mathrm{M} \mathrm{NaCl})$ and PSS $(1.0 \mathrm{mg} / \mathrm{mL}, 1 \mathrm{M} \mathrm{NaCl})$. Each immersion step was maintained for $20 \mathrm{~min}$, followed by thorough rinsing with deionized water. The periodic immersions in the PDDA and PSS solutions were repeatedly performed repeatedly in a four-time cycle to obtain (PDDA/PSS) 4.0 PEMs. Finally, the PSS-capped PEMs were thoroughly rinsed with deionized water and dried under pure nitrogen gas. The experimental preparation procedure is described in more detail in Supporting Information.

\subsection{Preparation of AFM probes}

This study uses two types of AFM probe. A triangular tipless probe (Bruker, NP-O10, silicon nitride) was adopted 
and used for force measurement between PEMs-coated AFM probe and PEMs substrate. Following this protocol, (PDDA/ PSS $)_{4.0}$ PEMs were also deposited on the AFM probe. Second, a rectangular gold probe (MikroMasch, CSC38/tipless/ $\mathrm{Cr}-\mathrm{Au}$ ) was applied for the force measurement between oil droplets and PEMs. Prior to use, the probe was rinsed with ethanol and water. Subsequently, hydrophobization method was performed as suggested in the literature (Tabor et al. 2011c; Shi et al. 2015; Mettu et al. 2017).

\subsection{Force measurements by AFM}

A multimode 8 AFM (Bruker) driven by NanoScope V controller was applied for force measurement. Prior to the force measurement, cantilevers were calibrated via a Thermal Tune method to obtain actual spring constant and deflection sensitivity. Interactions between PEMs coated probes and PEMs coated substrates were measured in $\mathrm{NaCl}$ solutions of different concentrations by directly lowering the probe to approach /retract from the substrate, Force curves were captured under a piezodriving rate of $0.5 \mu \mathrm{m} / \mathrm{s}$ and $Z$ ramp size of $1.5 \mu \mathrm{m}$ by setting the trig threshold at $5 \mathrm{nN}$.

To measure the droplet-substrate interaction, a tetradecane/water sample was initially prepared on the substrate according to the previous method described in literature with slight moderation (Gunning et al. 2004). The equilibrium interaction force was measured at a nominal velocity of $0.5 \mu \mathrm{m} / \mathrm{s}$ while the dynamic force was recorded by increasing the driving velocity to 1,4 and $12 \mu \mathrm{m} / \mathrm{s}$. To explore the effect of salinity, several sets of force measurements between a tetradecane droplet and the substrate in various concentrations of aqueous solutions of $\mathrm{NaCl}$ were performed by exchanging the dilute continuous phase with concentrated solutions, while the droplet (of radius $R=50 \pm 0.5 \mu \mathrm{m}$, Fig. S2) and substrate were left unchanged to eliminate the influence of droplet size. Various $\mathrm{NaCl}$ concentrations of 0.1 to1, 10 and $100 \mathrm{mM}$ were prepared for the continuous phase, respectively. The experimental formulations are described in more detail in Supporting Information.

\subsection{Theoretical model}

The SRYL model was applied here to provide a quantitative description of the interaction mechanism. The film drainage process is described by the film drainage equation shown in Eq. (1),

$\frac{\partial h(r, t)}{\partial t}=\frac{1}{12 \mu r} \frac{\partial}{\partial r}\left[r h(r, t)^{3} \frac{\partial p(r, t)}{\partial r}\right]$

where $h(r, t)$ is the intervening film thickness, $\mu$ is the viscosity of the continuous phase, $r$ is the radical coordinate, and $p(r, t)$ is the hydrodynamic pressure in the film. Figure 1a shows an illustration of the geometry between a droplet and substrate. Figure $1 \mathrm{~b}$ depicts a typical force curve and film thicknesses correspond to five vital points in the force curves. The five time instances are as follows: $T_{1}=0 \mathrm{~s}$ is the start of approach process (black line), $T_{2}$ is when the initial repulsion is measured (red line), $T_{3}$ is the time the minimum film thickness is reached during the whole process (immediately after the threshold force is reached, blue line), $T_{4}$ is when the minimum force (or maximum attractive force) of the retracting process is obtained (green line), and $T_{5}$ is the terminal of force measurement (pink line).
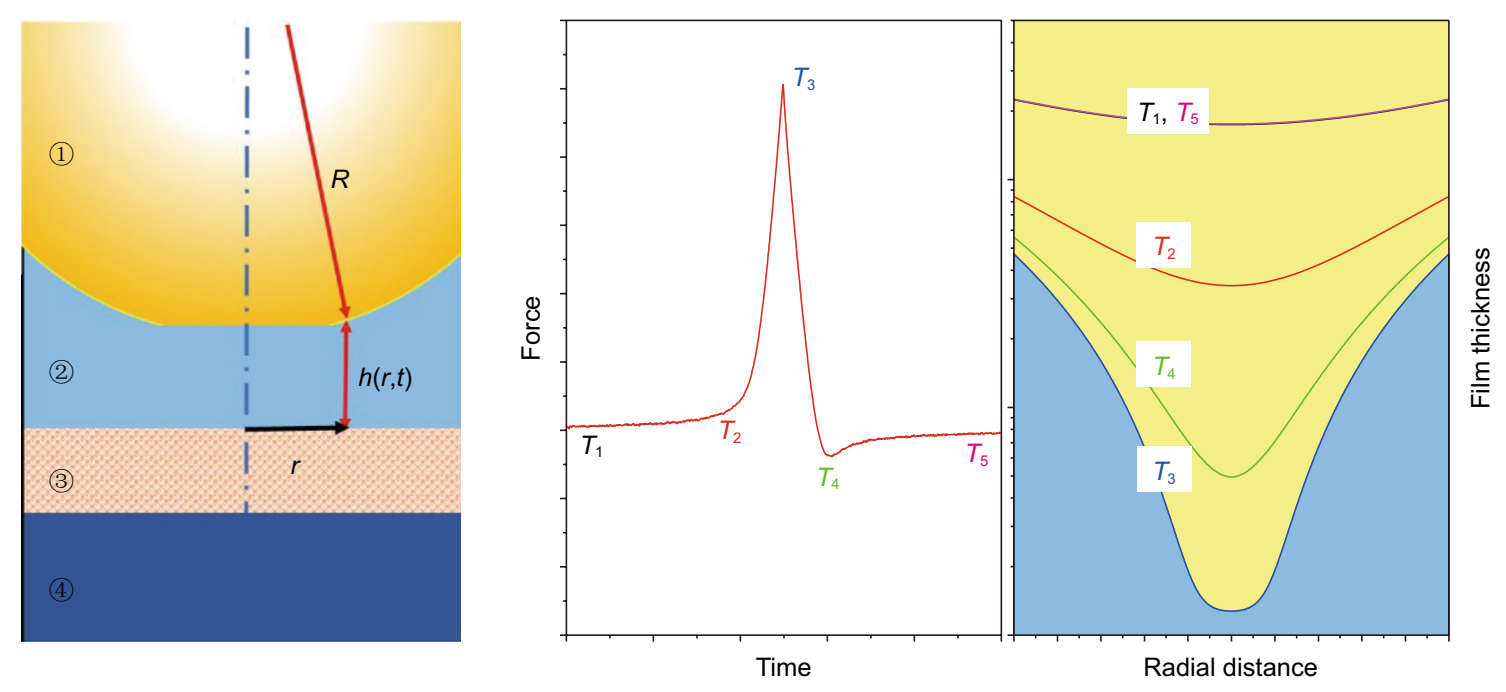

Fig. 1 a Schematic representation of the geometric conditions during the droplet-substrate interaction process where (1) is the tetradecane droplet, (2) is the aqueous solution, (3) is the PEMs and (4) is the silica wafer; b plots of time instances in the force curve and corresponding film thickness 
Droplet deformation as a result of interactions including disjoining pressure and hydrodynamic pressure is described by the augmented Young-Laplace equation (Eq. (2)),

$\frac{\sigma}{r} \frac{\partial}{\partial r}\left[r \frac{\partial h(r, t)}{\partial r}\right]=\frac{2 \sigma}{R}-p(r, t)-\Pi[h(r, t)]$

where $\sigma$ is the interfacial tension of the droplet, $R$ is the droplet radius, and $\Pi$ is the disjoining pressure.

The disjoining pressure is a function of the film thickness and consists of contributions from van der Waals (VDW) force and the electrical double layer (EDL) force, according to DLVO theory.

$\Pi[h(r, t)]=\Pi_{\mathrm{VDW}}[h(r, t)]+\Pi_{\mathrm{EDL}}[h(r, t)]$

The contribution of VDW interaction can be calculated following Eq. (4),

$\Pi_{\mathrm{VDW}}[h(r, t)]=-\frac{A_{\mathrm{H}}}{6 \pi h^{3}(r, t)}$

where $A_{\mathrm{H}}$ is the non-retarded Hamaker constant for droplet-water-PEMs system, which is estimated as $8.87 \times 10^{-21} \mathrm{~J}$ according to the Lifshitz-theory-based method suggested by Israelachvili (Israelachvili 2011).

The EDL interaction between PEM-coated cantilever and PEM-coated substrate can be calculated according to Eq. (5), and the EDL interaction between droplet and PEMs coated substrate is calculated using Eq. (6) according to the literature (Zhang et al. 2016b),

$\Pi_{\mathrm{EDL}}[h(r, t)]=64 k_{\mathrm{B}} T \rho_{\infty} \tanh ^{2}\left(\frac{z e \psi_{\mathrm{s}}}{4 k_{\mathrm{B}} T}\right) * \exp [-\kappa h(r, t)]$

$\Pi_{\mathrm{EDL}}[h(r, t)]=64 k_{\mathrm{B}} T \rho_{\infty} \tanh \left(\frac{z e \psi_{\mathrm{d}}}{4 k_{\mathrm{B}} T}\right) * \tanh \left(\frac{z e \psi_{\mathrm{s}}}{4 k_{\mathrm{B}} T}\right) * \exp [-\kappa h(r, t)]$

where $k_{\mathrm{B}}$ is the Boltzmann constant, $T$ is the absolute temperature, $\rho_{\infty}$ is the number density of ions in the aqueous solution, $z$ is the valency of the ion, $e$ is the electron charge, $\psi_{\mathrm{d}}$ and $\psi_{\mathrm{s}}$ are the surface potentials of the droplet and PEMs substrate, respectively, and $\kappa^{-1}$ is the Debye length that can be calculated using Eq. (7),

$\kappa^{-1}=\left(\frac{\sum_{i} \rho_{\infty i} e^{2} z_{i}^{2}}{\varepsilon_{0} \varepsilon k_{\mathrm{B}} T}\right)^{-\frac{1}{2}}$

The overall interaction force between droplet and the substrate is the integral of the hydrodynamic pressure and disjoining pressure based on the Derjaguin approximation,

$F=2 \pi \int_{0}^{\infty}(p(r, t)+\Pi(h(r, t))) r \mathrm{~d} r$

The above equations can be solved numerically with appropriate boundary conditions and initial conditions as given in Supporting Information.

\section{Results and discussion}

\subsection{Interactions between the PEM-coated probe and PEMs substrate in $\mathrm{NaCl}$ solutions}

Qualitative analysis on the charge properties of (PDDA/ PSS $)_{4.0}$ PEMs was performed by initially measuring the electrostatic interaction between (PDDA/PSS) 4.0 $_{\text {-coated }}$ cantilever and (PDDA/PSS $)_{4.0^{-}}$coated substrate. The equilibrium interaction forces are represented in Fig. 2 at the $\mathrm{NaCl}$ concentrations in the range 0.1-100 mM. Considering an electrolyte concentration to be as low as $0.1 \mathrm{mM}$, strong and long-range repulsions were measured between the two parallel surfaces as shown in Fig. 2a. A comparison of force curves was performed by the tenfold increase of $\mathrm{NaCl}$ concentration (Fig. 2b-d). Obviously, with the increase in the electrolyte concentration, the interaction range of the repulsion between two surfaces is successively compressed. The same trend was also deduced between a (PDDA/PSS) 4.0 -coated tip (tens of nanometers in diameter) and a (PDDA/PSS) 4.0 substrate (force curves are shown in Fig. S3 in Supporting Information).

Liu et al. (2015) demonstrated that the surface of the PSS-capped (PDDA/PSS $)_{4.0}$ PEMs were negatively charged with exclusive $\mathrm{Na}^{+}$ions being detected as counter ions. Therefore, it was concluded that the strong repulsion between the two negatively charged surfaces was caused by electrical double layer force. The theoretical analysis of the electrical double layer force between the two PSScapped surfaces related to the specific $\mathrm{NaCl}$ concentration was examined using Eq. (5), while the force vs. piezodisplacement (shown in Fig. S4) relations were then converted into force vs. distance curves following the method mentioned in the literature (Bowen and Hilal 2009; Butt et al. 2005). Since it is challenging to perform force measurement between a tipless cantilever and a planer substrate, the tipless cantilever and PEMs substrate is treated as finite surface-finite surface system, with an equivalent interacting area being estimated to fit experimental data in our study. The surface potentials of (PDDA/PSS) ${ }_{4.0}$ PEMs were fitted into the model and Fig. 2 depicts the deduced theoretical results using solid lines. Table S1 of Supporting Information lists the obtained surface potentials of (PDDA/PSS)4.0 PEMs in $\mathrm{NaCl}$ solutions.

\subsection{Interactions between tetradecane droplet and PEMs Substrate in $\mathrm{NaCl}$ solutions}

Figure 3 presents the equilibrium interactions of the tetradecane droplet approaching and withdrawing $(\text { PDDA/PSS })_{4.0}$ substrate under different electrolyte 

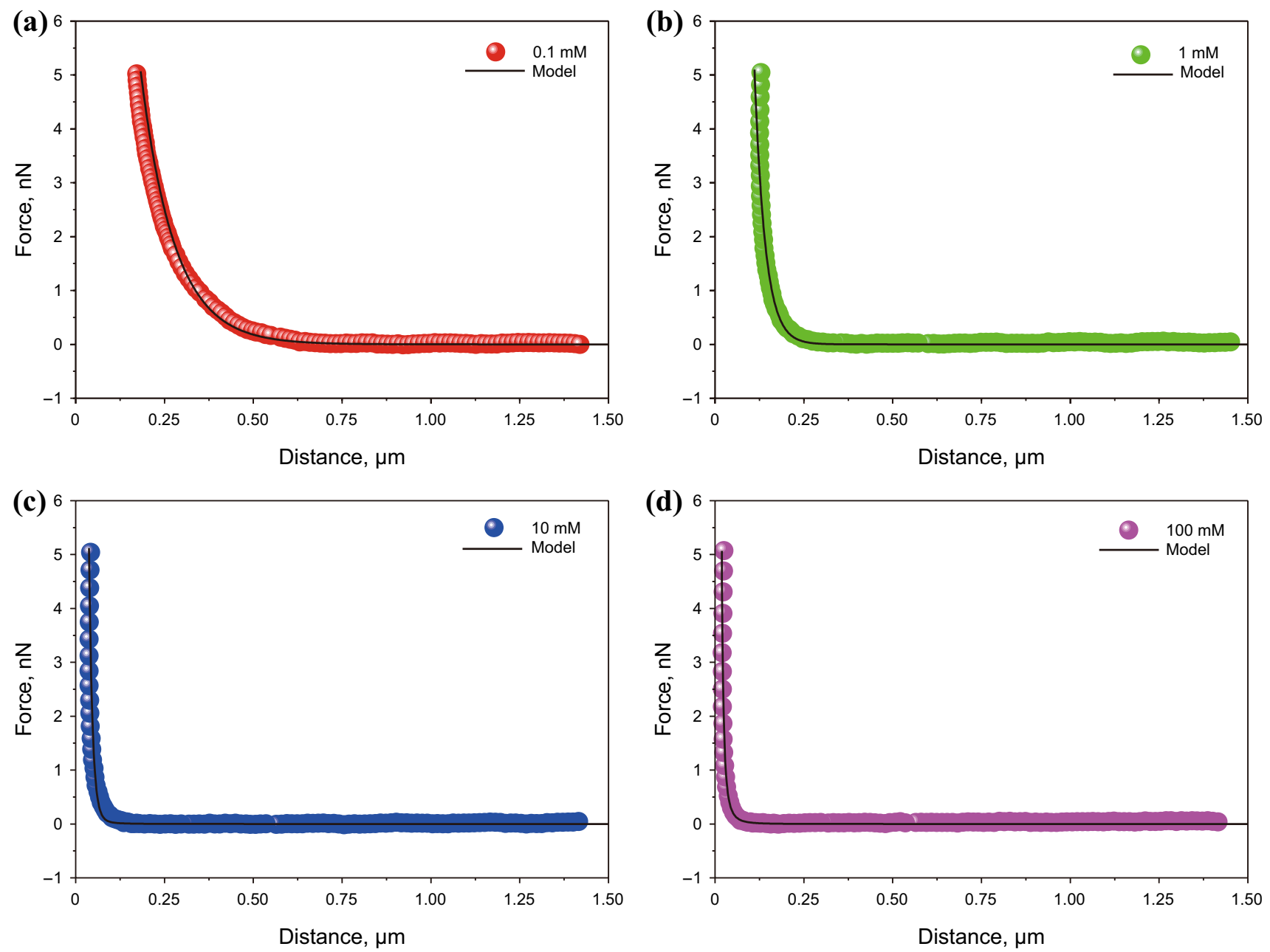

Fig. 2 Force curves measured between (PDDA/PSS) ${ }_{4 .}{ }^{-}$coated cantilever and (PDDA/PSS) $)_{4.0}$ substrate in a $0.1 \mathrm{mM} \mathrm{NaCl,} \mathrm{b} 1 \mathrm{mM} \mathrm{NaCl}, \mathbf{c}$ $10 \mathrm{mM} \mathrm{NaCl}$, and $\mathbf{d} 100 \mathrm{mM} \mathrm{NaCl}$ aqueous solution, respectively. The symbols represent the experimental results and solid lines show theoretical calculations. All the measurements were conducted under an equilibrium condition with a driving velocity of $500 \mathrm{~nm} / \mathrm{s}$

concentrations. Strong repulsion force was measured as the droplet approached PEMs substrate at low $\mathrm{NaCl}$ concentrations $(0.1 \mathrm{mM}$ and $1 \mathrm{mM})$ until the maximum force load $(5 \mathrm{nN})$ was reached with no attraction observed during the retract process. The increased electrolyte concentration resulted in a compressed interaction range for the repulsion, as clearly shown in Fig. 3. In essence, when the $\mathrm{NaCl}$ concentration increased to $10 \mathrm{mM}$, an attractive well emerged in the retracting curve. The observed attraction with the maximum close to $3 \mathrm{nN}$ was believed to result from the adhesion of droplet to the substrate other than hydrodynamic attraction (Dagastine et al. 2006, 2010; Tabor et al. 2013; Gunning et al. 2013; Vakarelski et al. $2010 \mathrm{~b}$ ), as the measurement was conducted under a driving velocity of $v=0.5 \mu \mathrm{m} / \mathrm{s}$. As the $\mathrm{NaCl}$ concentration reached $100 \mathrm{mM}$, "jump-in" occurred in the approaching process (denoted by the arrow shown in inset of Fig. 3), which indicated the attachment of oil droplet to PEMs. A more prominent adhesion force (approximately $17.2 \mathrm{nN}$ in Fig. 3) was measured in the retraction process, followed immediately by a "jump-out" event. Repeated measurements were also performed between air bubbles and the PEMs substrate under equilibrium conditions (Fig. S5 in Supporting Information) with the observed trend being the same as that shown in Fig. 3. Therefore, the PSScapped (PDDA/PSS $)_{4.0}$ PEMs showed a salinity-sensitive oil repellency in water as an EDL repulsion-dominated tendency was indicated.

The dynamic interaction between the tetradecane droplet and (PDDA/PSS) ${ }_{4.0}$ substrate was measured in comparison with equilibrium interaction by increasing the piezodriving velocity to 1,4 and $12 \mu \mathrm{m} / \mathrm{s}$, respectively. Figure 4 shows the force curves of the droplet interacting with PEMs substrate in $0.1 \mathrm{mM} \mathrm{NaCl}$ solution. The obtained force curves showed strong velocity dependence, while the approach curves of Fig. $4 a-d$ indicate 


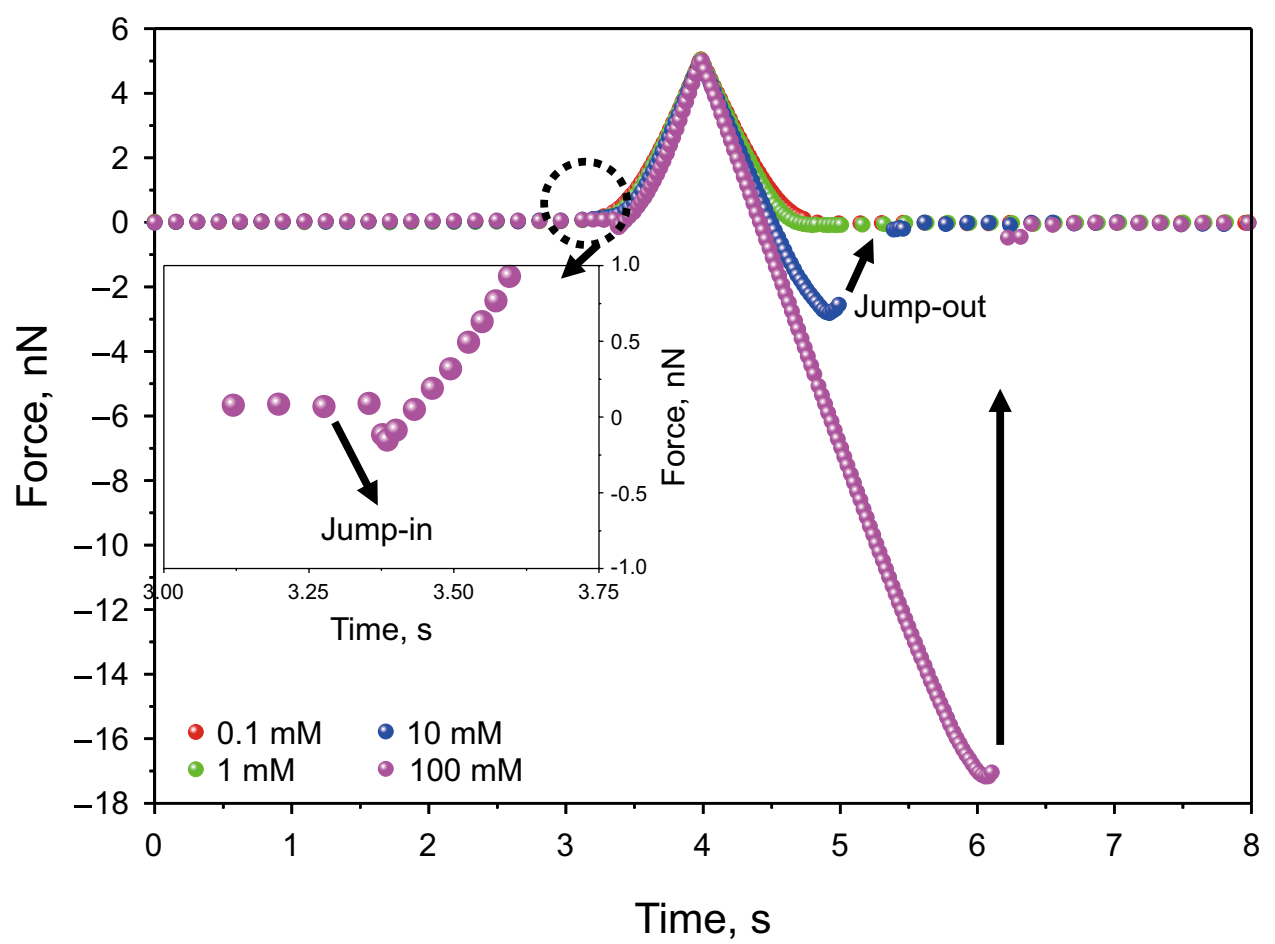

Fig. 3 Equilibrium interaction curves measured between tetradecane droplet and (PDDA/PSS) ${ }_{4.0}$ substrate in NaCl solutions with driving velocity $v=0.5 \mu \mathrm{m} / \mathrm{s}$

velocity-enhanced hydrodynamic repulsion in combination with velocity-independent EDL force. The maximum attraction force in the retracting curve was observed as a function of velocity. A quantitative analysis of the experimental data was evaluated by applying the SRYL model. The predicted force curves are shown as solid lines in Fig. 4 and indicated to be consistent with experimental results.

Theoretical calculations were performed for the intervening film thicknesses between the droplet and PEMs substrate in $0.1 \mathrm{mM} \mathrm{NaCl}$. The film thicknesses of five typical time instances were chosen and are depicted in Fig. 5. The theoretical calculations indicated a minimum film thickness of about $70 \mathrm{~nm}$ between the oil droplet and the PEMs substrate in $0.1 \mathrm{mM} \mathrm{NaCl}$ solution. This demonstrated a strong hindrance of further approaches by EDL repulsion combined with hydrodynamic force. Figure S6 depicts disjoining pressure profiles as a function of distance based on DLVO theory (Israelachvili 2011), demonstrating that EDL repulsion dominates as the overall pressure for a large distance span.

Consistency was also found between experimental data and theoretical calculations for droplet-PEMs interactions in $1 \mathrm{mM} \mathrm{NaCl}$ solution. This indicated a proper description of the interaction process using the SRYL model. Figures S7, S8, and S9 in Supporting Information show the force curves, film thicknesses, and disjoining pressure profiles, respectively.
Upon increasing in $\mathrm{NaCl}$ concentration to $10 \mathrm{mM}$, a proper description of the approaching process yet underestimated attracting force in the retracting process is shown in Fig. $6 \mathrm{a}, \mathrm{b}$ at low driving velocities $(0.5$ and $1 \mu \mathrm{m} / \mathrm{s})$. While consistency between the measured force and calculations was displayed under moderate $(4 \mu \mathrm{m} / \mathrm{s}$ in Fig. $6 \mathrm{c})$ and high driving (12 $\mu \mathrm{m} / \mathrm{sin}$ Fig. $6 \mathrm{~d})$ velocities. The inconsistency at low velocities indicated that the attraction was not attributed to the film drainage but should be counted as a result of underestimated VDW attraction or other neglected attractive interactions. This underestimation appeared to be eliminated by the increase of driving velocity as hydrodynamic attraction stem from film drainage process dominates. The film evolution in $10 \mathrm{mM} \mathrm{NaCl}$ solution is shown in Fig. S10. The minimum film thickness at equilibrium condition was calculated as $8.5 \mathrm{~nm}$. The increase in approach velocity resulted in a shrunken flattening region of the film in close proximity (blue lines in the figure) with a thickened intervening liquid film at maximum attraction points (green lines in the figure). Figure S11 depicts the disjoining pressure profiles.

Figure 7 shows the force curves of the droplet and substrate in $100 \mathrm{mM} \mathrm{NaCl}$ solution. The discrepancy was observed from $v=0.5 \mu \mathrm{m} / \mathrm{s}$ to $\nu=4 \mu \mathrm{m} / \mathrm{s}$, while consistency was determined as $v=12 \mu \mathrm{m} / \mathrm{s}$. The theoretically calculated film thickness and disjoining pressure are plotted in Figs. S12 and S13. Herein, we could draw conclusions that the adhesion force between droplet and PEMs substrate can be 

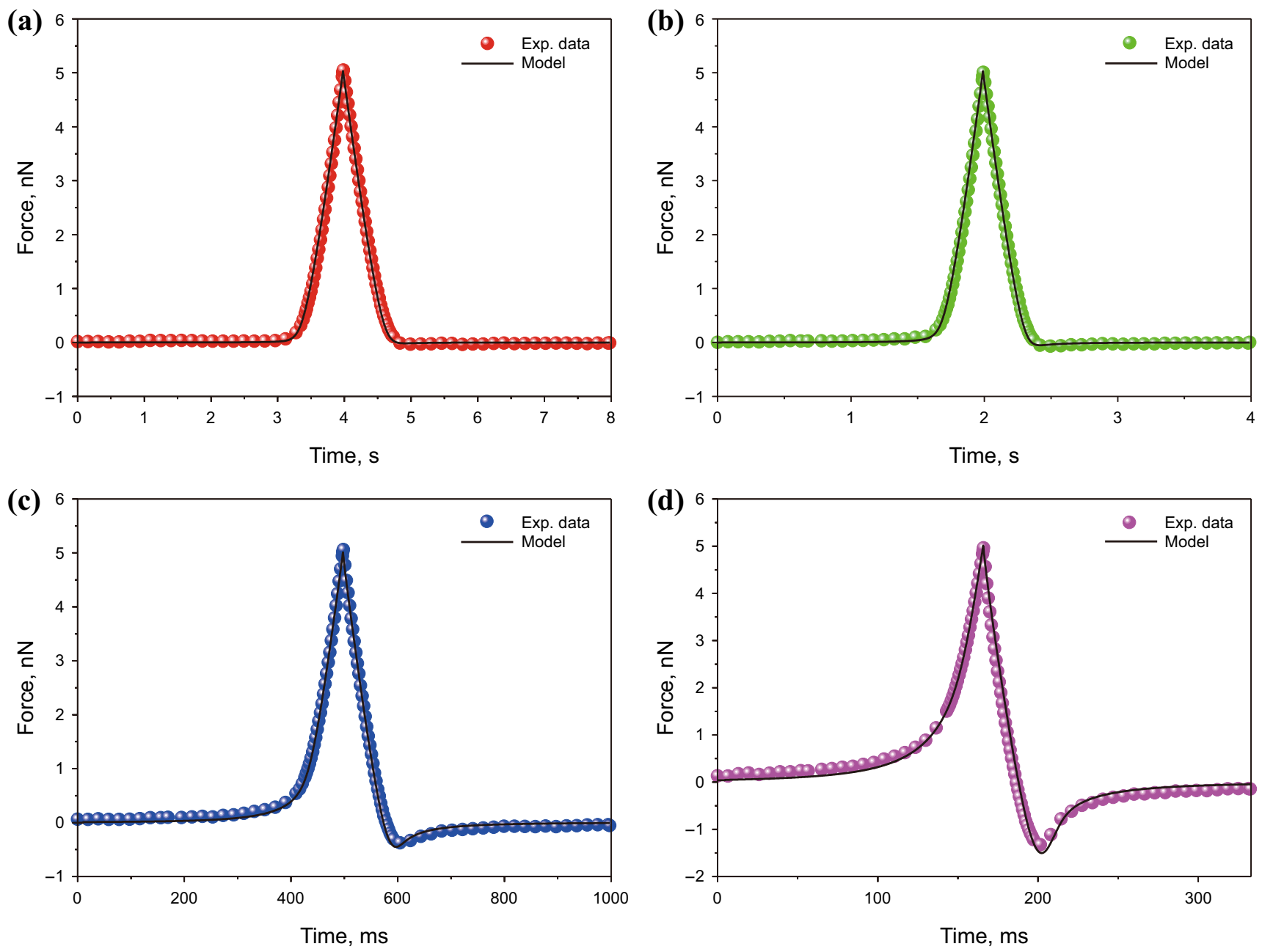

Fig. 4 Equilibrium and dynamic interactions between tetradecane droplet and the (PDDA/PSS) (.. $_{\text {. }}$ substrate in $0.1 \mathrm{mM} \mathrm{NaCl}$ at a driving velocity of a $0.5 \mu \mathrm{m} / \mathrm{s}, \mathbf{b} 1 \mu \mathrm{m} / \mathrm{s}, \mathbf{c} 4 \mu \mathrm{m} / \mathrm{s}$, and $\mathbf{d} 12 \mu \mathrm{m} / \mathrm{s}$, respectively. The symbols represent the experimental results and the solid lines represent the theoretical calculations

counteracted by increase in the approaching velocity, but the origin of attraction remains ambiguous.

\subsection{Discussion on the effect of PEMs surface roughness}

An adhesion-like attractive force was measured between the droplet and oil-repellent PEMs in the $10 \mathrm{mM}$ and $100 \mathrm{mM}$ $\mathrm{NaCl}$ solutions. With the aid of abundant ions introduced into the surrounding liquid phase, the EDL was suppressed into the distance within the domination of the short-ranged attractive interactions (Fig. S11). The adhesion force was believed to have resulted from VDW force and other nonDLVO forces (Tang et al. 2018a, b; Ma et al. 2015; Donaldson et al. 2015; Kristiansen et al., 2014; Rios-Carvajal et al., 2018). In present studied system, the PSS-capped PEMs achieved hydrophilicity by orienting anionic sulfonate $\left(\mathrm{SO}_{3}{ }^{-}\right)$moieties in an orderly and upright manner to maximize its surface charge density upon sufficient immersion in water as reported in Liu et al.'s work (Liu et al. 2015). Therefore, the contribution of the hydrophobic attraction (Cui et al. 2016, 2017, 2018; Xie et al. 2017a, b) to the adhesion force was not considered though tetradecane droplet is hydrophobic.

Here, it is possible to attribute the measured attractive force to either overvalued EDL repulsion or underestimated VDW attraction. This is comprehensible if we note that the surface of the substrate was treated as atomically smooth in the above calculation (see schematic a of Fig. 1), while the LbL fabricated multilayers virtually possess an equivalent surface roughness (see schematic of equivalent film thickness in Fig. 8). The influence of this nanoscale roughness is inconspicuous at low electrolyte concentrations when the repulsive EDL is sufficiently thick while non-negligible when EDL is suppressed within the nanometer range by high salinity. Therefore, equivalent film thickness rather 

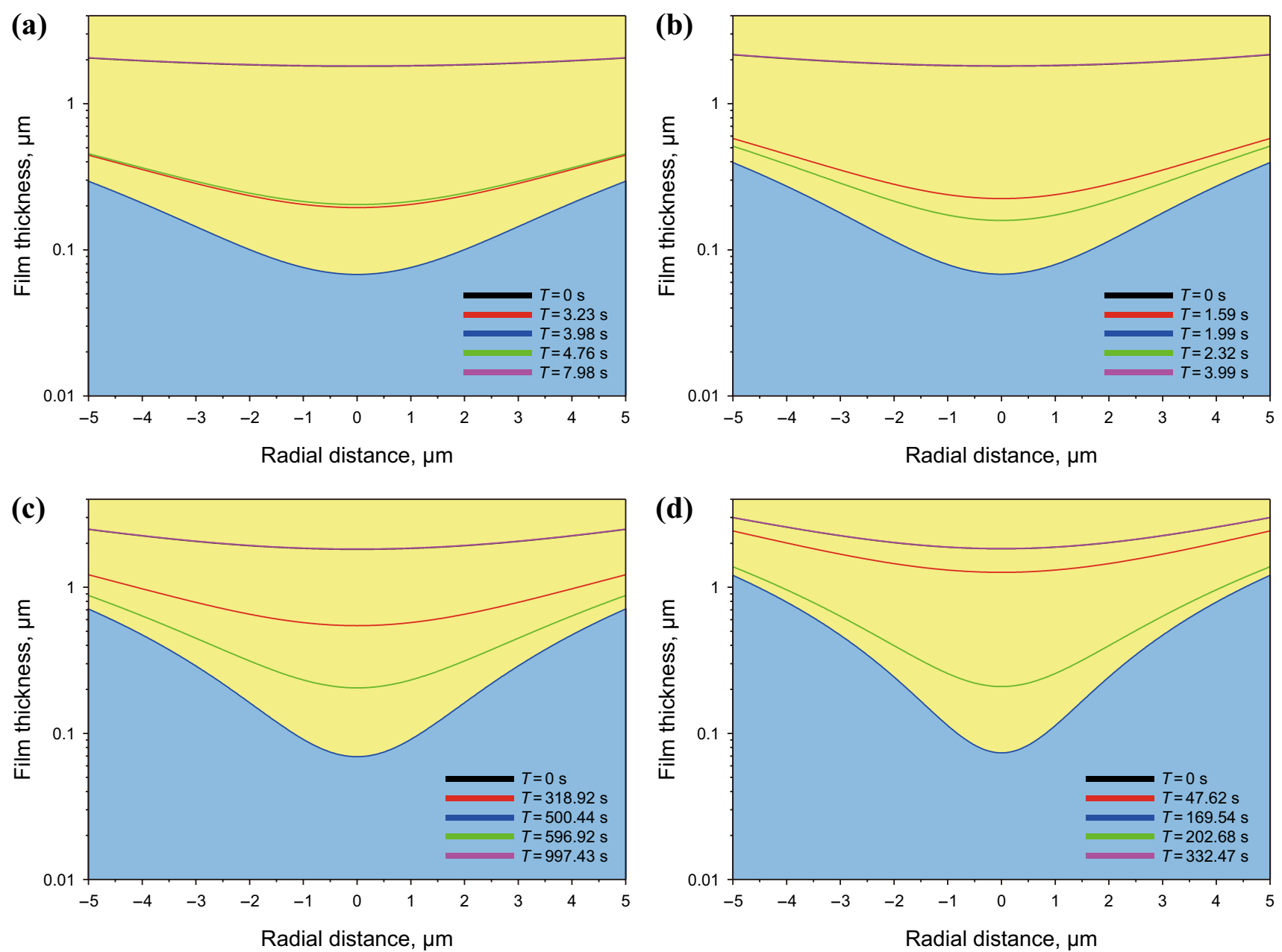

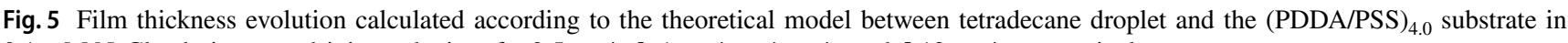
$0.1 \mathrm{mM} \mathrm{NaCl}$ solution, at a driving velocity of a $0.5 \mu \mathrm{m} / \mathrm{s}, \mathbf{b} 1 \mu \mathrm{m} / \mathrm{s}, \mathbf{c} 4 \mu \mathrm{m} / \mathrm{s}$, and $\mathbf{d} 12 \mu \mathrm{m} / \mathrm{s}$, respectively

than thickness of the actual uneven liquid film should be considered. This nanoscale roughness of the PEMs means that a thinner EDL and reduced surface potential can be anticipated. The explanation for the decrease in surface potential stems from an intriguing observation reported in the literature (Liu et al. 2015). It was demonstrated that the surface charge density of PSS-capped surfaces was sensitive to the orientation of phenyl $(\mathrm{Ph})$ moieties and sulfonate moieties. In close contact with oil, the sulfonate moieties were distributed parallel to the surface plane, which resulted in an obviously reduced surface charge density. In this consideration, the interaction between the droplet and PEMs in $10 \mathrm{mM}$ and $100 \mathrm{mM} \mathrm{NaCl}$ solution was recalculated by modulation of the surface potential. The modulated surface potentials of PEMs and EDL thicknesses are listed in Table S2 in Supporting Information, and the adjusted results with $10 \mathrm{mM} \mathrm{NaCl}$ are shown in Fig. 9 . The recalculated film thickness (Fig. 9c) demonstrates a deduction of approximately $5 \mathrm{nn}$ as compared to the previous results (Fig. S10a). Another interesting phenomenon worth mentioning is that increasing the $\mathrm{NaCl}$ concentration to $100 \mathrm{mM}$ leads to an observable slight increase in the refractive index (RI) of (PDDA/PSS) ${ }_{4.0}$ PEMs following the results deduced in the literature (Zerball et al. 2015). This indicated an increase in Hamaker constant according to the Lifshitz theory. Based on this consideration, it may be hypothesized that the increase in VDW interaction also contributes to the attraction experienced during the retract process.

For the $100 \mathrm{mM} \mathrm{NaCl}$ concentration, EDL is almost screened by the surrounding ions as a "jump-in" occurs in the approaching process, which indicates the "attachment" 

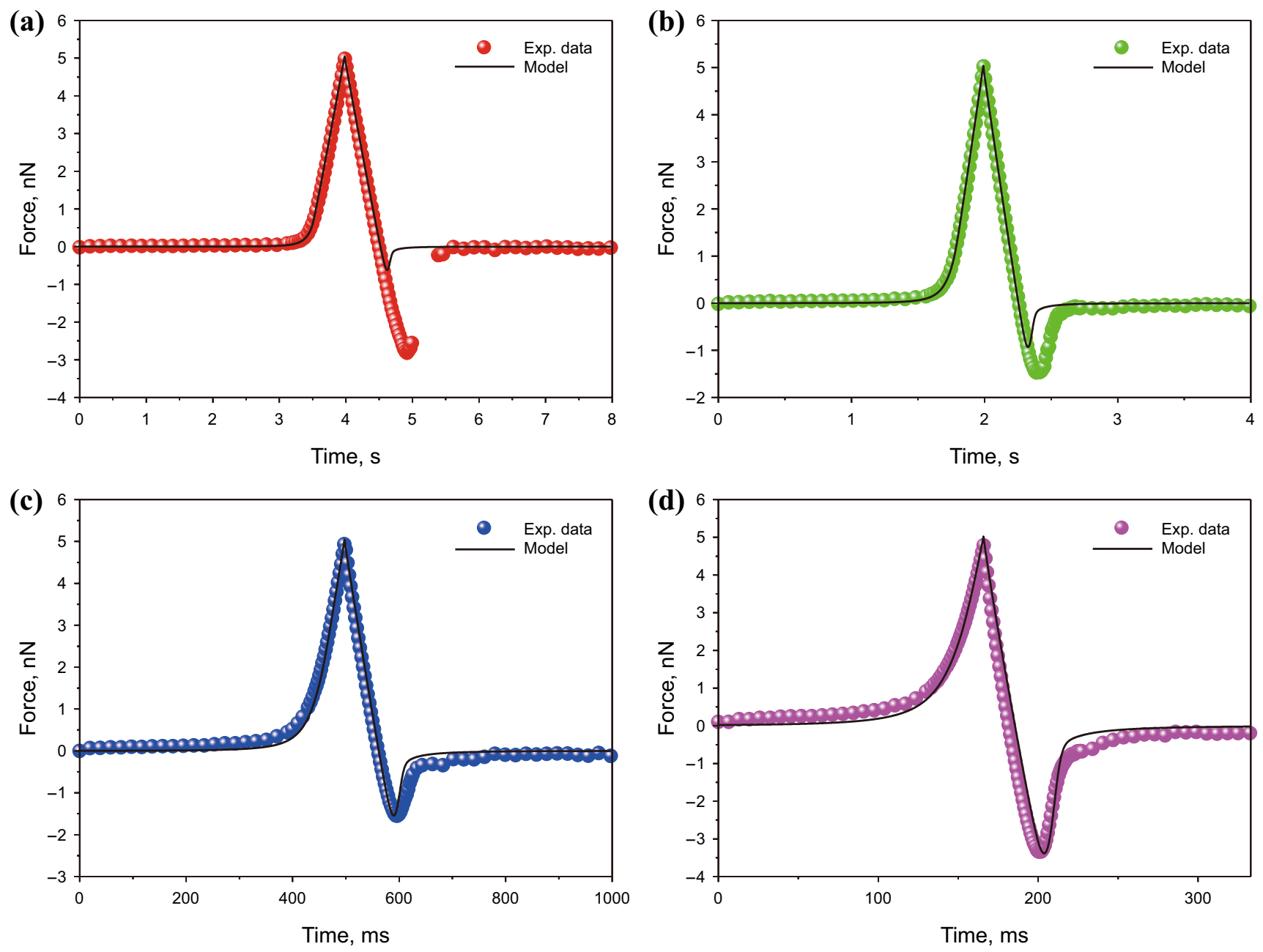

Fig. 6 Equilibrium and dynamic interactions between a tetradecane droplet and the (PDDA/PSS) 4.0 substrate in $10 \mathrm{mM} \mathrm{NaCl}$ at driving velocities of a $0.5 \mu \mathrm{m} / \mathrm{s}, \mathbf{b} 1 \mu \mathrm{m} / \mathrm{s}$, c $4 \mu \mathrm{m} / \mathrm{s}$, and $\mathbf{d} 12 \mu \mathrm{m} / \mathrm{s}$, respectively. The symbols represent the experimental data and the solid lines depict the theoretical calculations

of droplet onto the substrate. Noting that the nanoscale surface roughness of PEMs behaves as a "brush" (Kobayashi et al. 2012) and water is trapped by hydration, it is conceivable that the oil droplet was repelled by the nanoscale surface roughness rather than becoming completely attached to the surface. The "brush" effect of PEMs is characterized by a short-ranged steric hindrance interaction represented by the exponential equation (Israelachvili 2011), $\Pi_{\mathrm{SH}}=C_{0} \exp \left[h(r, t) / D_{0}\right]$, is introduced in the calculation of the disjoining pressure as shown in Fig. 10. Detailed values in calculating steric hindrance are given in Supporting Information. Figure 11 shows the modulated force curves and corresponding film thickness evolution.
The consistency between experimental results and calculation demonstrates a proper interaction mechanism. The "jump-out" behavior captured in the retracting curve under equilibrium conditions indicates that the droplet detached from the "brush" segments of the substrate, although adhesion force due to VDW attraction was measured. This brush-like surface configuration tends to render a superior oil repellency of the studied PEMs even at a relatively high salinity (500 $\mathrm{mM}$ ) as reported in our previous study (Jin et al. 2019). 

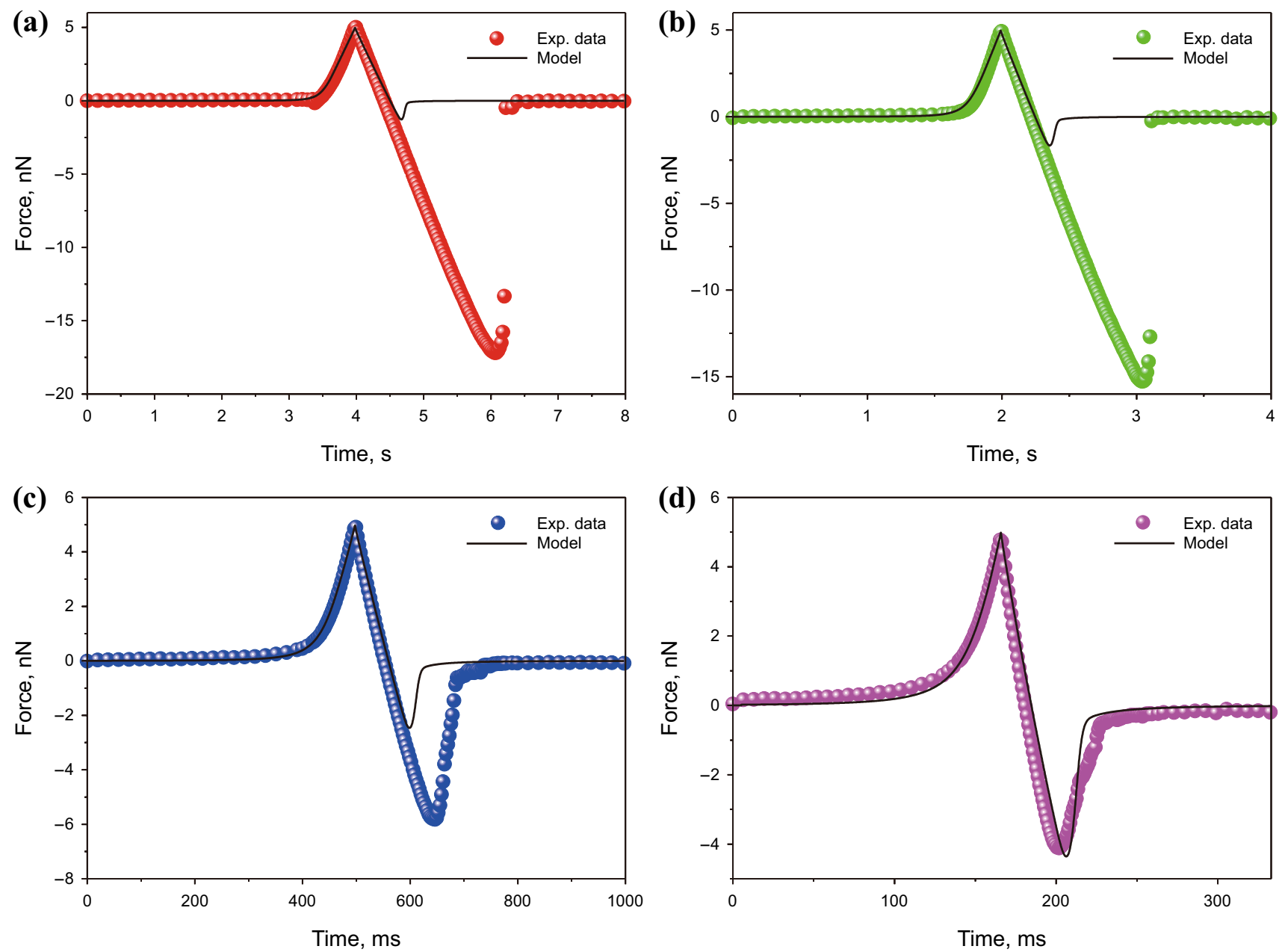

Fig. 7 Equilibrium and dynamic interactions between a tetradecane droplet and the (PDDA/PSS) 4.0 substrate in $100 \mathrm{mM} \mathrm{NaCl}$ at driving velocities of a $0.5 \mu \mathrm{m} / \mathrm{s}, \mathbf{b} 1 \mu \mathrm{m} / \mathrm{s}, \mathbf{c} 4 \mu \mathrm{m} / \mathrm{s}$, and $\mathbf{d} 12 \mu \mathrm{m} / \mathrm{s}$, respectively. The symbols represent the experimental data and the solid lines depict the theoretical calculations

\section{Conclusions}

In this work, the interaction between (PDDA/PSS $)_{4.0}$ PEM-coated probes and substrates in aqueous solution has been studied. Repulsion was measured between the negatively charged PEMs. A successive increase in the electrolyte concentration of the continuous phase showed a suppressed interaction range for the repulsion. The salinity-related repulsion was analyzed and the charge property related to PSS-capped PEMs was gained. The interactions between the tetradecane droplet and PEMs substrate under various salinities were explored by droplet probe AFM technique. Subsequently, quantitative analysis of the interaction process was performed based on the SRYL model. The results presented a proper explanation of the interactions between the oil droplet and the charged PEMs substrate in solutions of low electrolyte

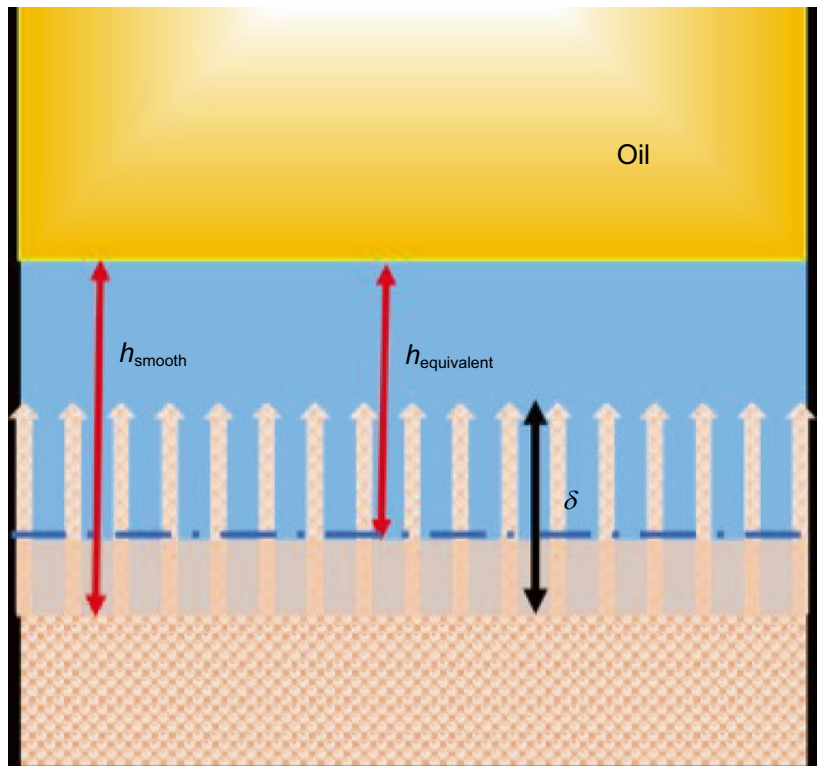

Fig. 8 Schematic of the surface roughness and equivalent film thickness 
concentration $(0.1$ and $1 \mathrm{mM})$ under both equilibrium and hydrodynamic conditions. As the electrolyte concentration was increased to moderate $(10 \mathrm{mM})$ and then to a high level $(100 \mathrm{mM})$, discrepancy during the retraction process was found and thereafter considered to be caused by weakened EDL interaction due to the nanoscale surface roughness combined with the orientation of the hydrated anionic benzenesulfonate moieties. The roughness of the fabricated PEMs was believed to contribute to a "brush" effect when oil droplet reached close contact with the oleophobic PEMs. A short-range steric hindrance was introduced into the disjoining pressure to simulate this "brush" effect. The present results further verified that the PSS-capped PEMs remained stable underwater lipophobicity against high salinity, which enhances its potential for applications in surface modification and anti-fouling. In the future works, more rigorous analysis of Hamaker constant and VDW force between oil droplet
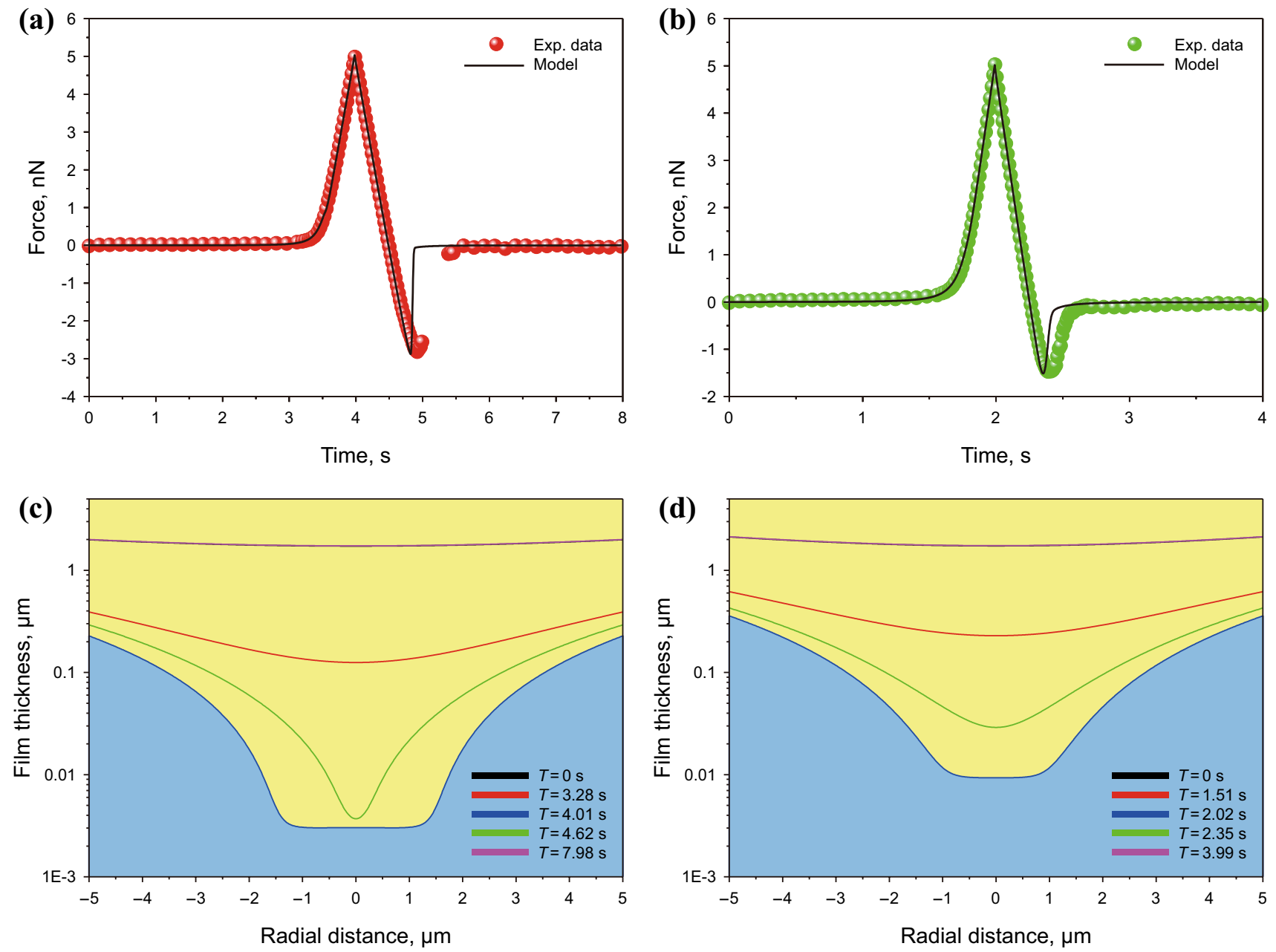

Fig. 9 Equilibrium and dynamic interactions between a tetradecane droplet and the (PDDA/PSS $)_{4.0}$ substrate in $10 \mathrm{mM} \mathrm{NaCl}$ with driving velocities of $\mathbf{a} 0.5 \mu \mathrm{m} / \mathrm{s}$ and $\mathbf{b} 1 \mu \mathrm{m} / \mathrm{s}$. The symbols represent the experimental data and the solid lines show the theoretical calculations. The theoretically recalculated film thickness evolution between tetradecane droplet and the (PDDA/PSS) $)_{4.0}$ substrate in $10 \mathrm{mM} \mathrm{NaCl}$ at $\mathbf{c} 0.5 \mu \mathrm{m} / \mathrm{s}$ and $\mathbf{d}$ $1 \mu \mathrm{m} / \mathrm{s}$ driving velocities 


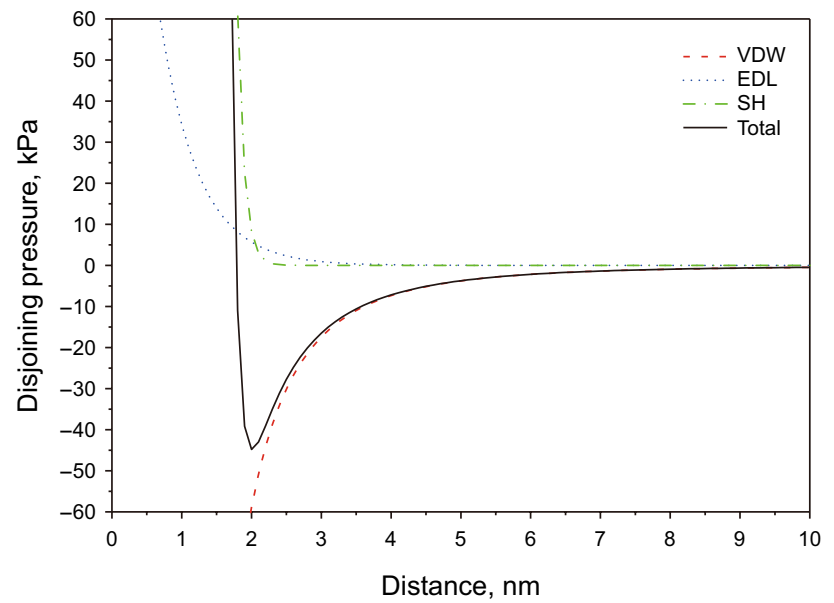

Fig. 10 Theoretically calculated disjoining pressure as a function of the separation of $100 \mathrm{mM} \mathrm{NaCl}$ system that includes VDW interaction, modulated EDL interaction, steric hindrance $(\mathrm{SH})$ and the overall disjoining pressure
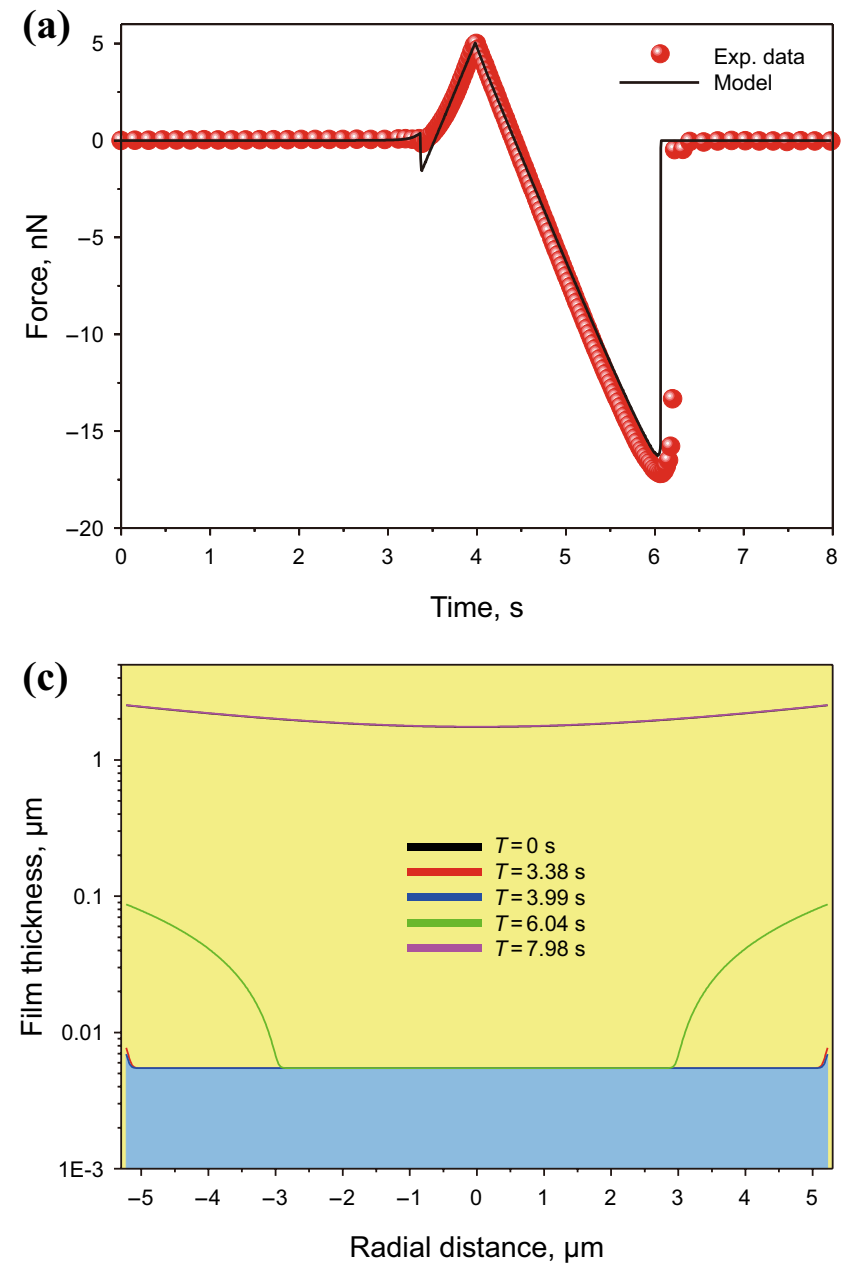

and as-prepared PEMs in the presence of concentrated $\mathrm{NaCl}$ solutions is demanded in future works.

Acknowledgements The authors wish to thank the National Natural Science Foundation of China (51774303, 51422406, 51534007), the National Science and Technology Specific Project (2016ZX05028-004001), and 111 Project (B18054) for providing support for this research.

Author contributions The manuscript was written through contributions of all authors. All authors have given approval to the final version of the manuscript.

\section{Compliance with ethical standards}

Conflict of interest The authors declare no competing financial interest.
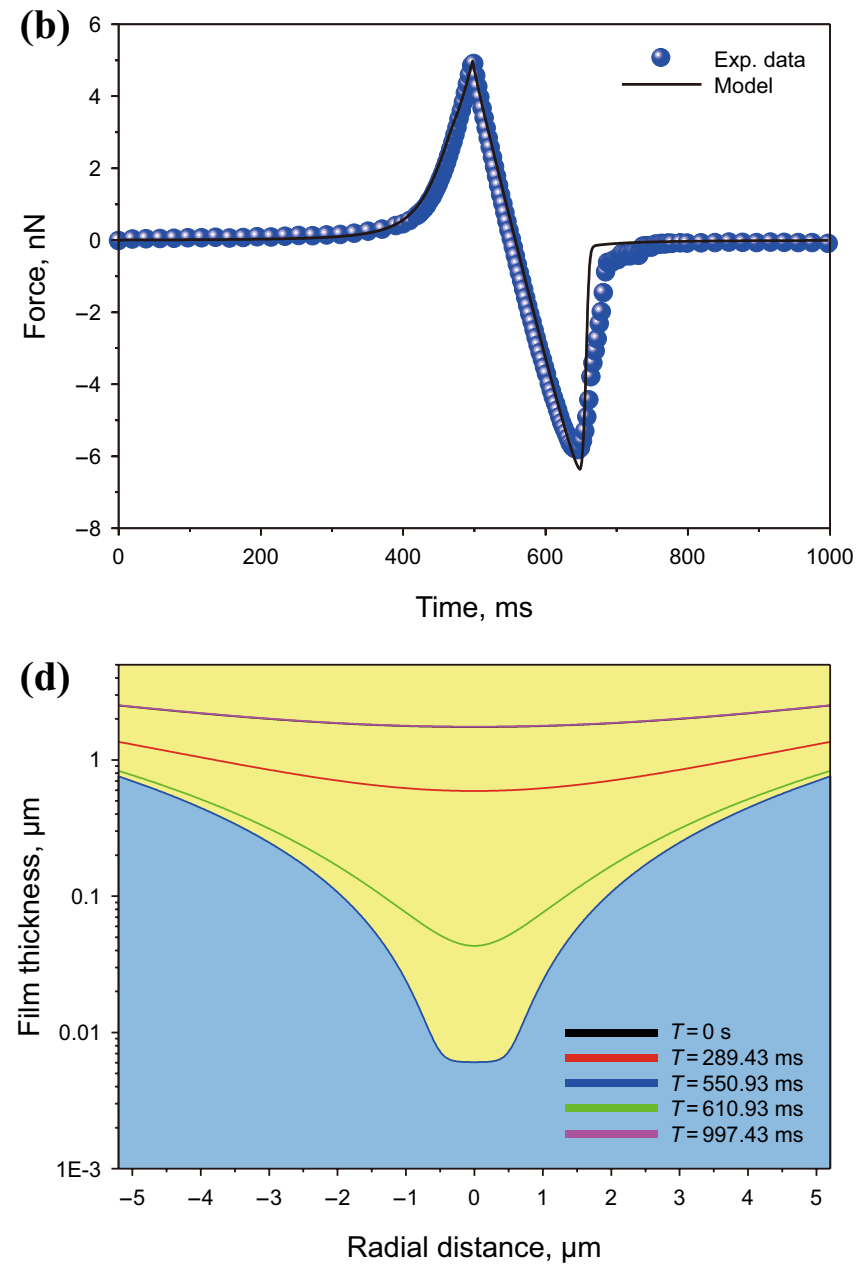

Fig. 11 Equilibrium and dynamic interactions between a tetradecane droplet and the (PDDA/PSS) $)_{4.0}$ substrate in $100 \mathrm{mM} \mathrm{NaCl}$ at driving velocities of $\mathbf{a} 0.5 \mu \mathrm{m} / \mathrm{s}$ and $\mathbf{b} 4 \mu \mathrm{m} / \mathrm{s}$. The symbols represent the experimental data and the solid lines show the theoretical calculations. The theoretically recalculated film thickness evolution between the tetradecane droplet and (PDDA/PSS) 4.0 substrate in $10 \mathrm{mM} \mathrm{NaCl}$ at $\mathbf{c} 0.5 \mu \mathrm{m} / \mathrm{s}$ and d $4 \mu \mathrm{m} / \mathrm{s}$ driving velocities 
Open Access This article is licensed under a Creative Commons Attribution 4.0 International License, which permits use, sharing, adaptation, distribution and reproduction in any medium or format, as long as you give appropriate credit to the original author(s) and the source, provide a link to the Creative Commons licence, and indicate if changes were made. The images or other third party material in this article are included in the article's Creative Commons licence, unless indicated otherwise in a credit line to the material. If material is not included in the article's Creative Commons licence and your intended use is not permitted by statutory regulation or exceeds the permitted use, you will need to obtain permission directly from the copyright holder. To view a copy of this licence, visit http://creativecommons.org/licenses/by/4.0/.

\section{References}

Ahmadi S, Hosseini M, Tangestani E, et al. Wettability alteration and oil recovery by spontaneous imbibition of smart water and surfactants into carbonates. Pet Sci. 2020;17:712-21. https://doi. org/10.1007/s12182-019-00412-1.

Aston DE, Berg JC. Thin-film hydrodynamics in fluid interface-atomic force microscopy. Ind Eng Chem Res. 2002;41(3):389-96. https ://doi.org/10.1021/ie0101240.

Balasuriya TS, Dagastine RR. Interaction forces between bubbles in the presence of novel responsive peptide surfactants. Langmuir. 2012;28(50):17230-7. https://doi.org/10.1021/la304351a.

Binnig G, Quate CF, Gerber C. Atomic force microscope. Phys Rev Lett. 1986;56:930-3. https://doi.org/10.1103/PhysRevLett.56.930.

Bowen R, Hilal N. Atomic force microscopy in process engineering. Oxford: Elsevier; 2009.

Butt HJ, Cappella B, Kappl M. Force measurements with the atomic force microscope: technique, interpretation and applications. Surf Sci Rep. 2005;59(1-6):1-152. https://doi.org/10.1016/j.surfr ep.2005.08.003

Cao L, Price TP, Weiss M, et al. Super water- and oil-repellent surfaces on intrinsically hydrophilic and oleophilic porous silicon films. Langmuir. 2008;24(5):1640-3. https://doi.org/10.1021/la703401f.

Chan DYC, Dagastine RR, White LR. Forces between a rigid probe particle and a liquid interface: I. The repulsive case. J Colloid Interface Sci. 2001;236(1):141-54. https://doi.org/10.1006/ jcis.2000.7400.

Chan DYC, Klaseboer E, Manica R. Film drainage and coalescence between deformable drops and bubbles. Soft Matter. 2011a;7(6):2235-64. https://doi.org/10.1039/C0SM00812E.

Chan DYC, Klaseboer E, Manica R. Theory of non-equilibrium force measurements involving deformable drops and bubbles. Adv Colloid Interface Sci. 2011b;165(2):70-90. https://doi.org/10.1016/j. cis.2010.12.001.

Chang CC, Kolewe KW, Li Y, et al. Underwater superoleophobic surfaces prepared from polymer zwitterion/dopamine composite coatings. Adv Mater Interfaces. 2016;3(6):1500521. https://doi. org/10.1002/admi.201500521.

Cheng G, Liao M, Zhao D, et al. Molecular understanding on the underwater oleophobicity of self-assembled monolayers: zwitterionic versus nonionic. Langmuir. 2017;33(7):1732-41. https ://doi.org/10.1021/acs.langmuir.6b03988.

Cui X, Shi C, Xie L, et al. Probing interactions between air bubble and hydrophobic polymer surface: impact of solution salinity and interfacial nanobubbles. Langmuir. 2016;32(43):11236-44. https://doi.org/10.1021/acs.langmuir.6b01674.

Cui X, Shi C, Zhang S, et al. Probing the effect of salinity and $\mathrm{pH}$ on surface interactions between air bubbles and hydrophobic solids: implications for colloidal assembly at air/water interfaces. Chem Asian J. 2017;12(13):1568-77. https://doi.org/10.1002/ asia. 201700388
Cui X, Liu J, Xie L, et al. Modulation of hydrophobic interaction by mediating surface nanoscale structure and chemistry, not monotonically by hydrophobicity. Angew Chem Int Ed. 2018;57(37):11903-8. https://doi.org/10.1002/anie.201805137.

Dagastine RR, White LR. Forces between a rigid probe particle and a liquid interface: II. The general case. J Colloid Interface Sci. 2002;247(2):310-20. https://doi.org/10.1006/jcis.2001.8111.

Dagastine RR, Stevens GW, Chan DYC, et al. Forces between two oil drops in aqueous solution measured by AFM. J Colloid Interface Sci. 2004a;273(1):339-42. https://doi.org/10.1016/j. jcis.2003.11.001.

Dagastine RR, Prieve DC, White LR. Forces between a rigid probe particle and a liquid interface: III. Extraction of the planar half-space interaction energy E(D). J Colloid Interface Sci. 2004b;269(1):84-96. https://doi.org/10.1016/S0021 -9797(03)00673-8.

Dagastine RR, Manica R, Carnie SL, et al. Dynamic forces between two deformable oil droplets in water. Science. 2006;313(5784):210-3. https://doi.org/10.1126/science.1125527.

Dagastine RR, Webber GB, Manica R, et al. Viscosity effects on hydrodynamic drainage force measurements involving deformable bodies. Langmuir. 2010;26(14):11921-7. https://doi.org/10.1021/ la1012473.

Decher G, Schlenoff JB. Multilayer thin films: sequential assembly of nanocomposite materials. Weinheim: Wiley; 2003.

Donaldson SH, Røyne A, Kristiansen K, et al. Developing a general interaction potential for hydrophobic and hydrophilic interactions. Langmuir. 2015;31(7):2051-64. https://doi.org/10.1021/ la502115g.

Ehsan GE, Rafat PR, Masoud RM. Enhancing the spontaneous imbibition rate of water in oil-wet dolomite rocks through boosting a wettability alteration process using carbonated smart brines. Pet Sci. 2019;16(6):1361-73. https://doi.org/10.1007/s1218 2-019-0355-1.

Ghostine RA, Markarian MZ, Schlenoff JB. Asymmetric growth in polyelectrolyte multilayers. J Am Chem Soc. 2013;135(20):763646. https://doi.org/10.1021/ja401318m.

Gunning AP, Mackie AR, Wilde PJ, et al. Atomic force microscopy of emulsion droplets: probing droplet-droplet interactions. Langmuir. 2004;20(1):116-22. https://doi.org/10.1021/la034835+.

Gunning AP, Kirby AR, Wilde PJ, et al. Probing the role of interfacial rheology in the relaxation behaviour between deformable oil droplets using force spectroscopy. Soft Matter. 2013;9:11473-9. https://doi.org/10.1039/C3SM52341A.

Guo P, Zheng Y, Wen M, et al. Icephobic/anti-icing properties of micro/nanostructured surfaces. Adv Mater. 2012;24(19):2642-8. https://doi.org/10.1002/adma.201104412.

Israelachvili JN. Intermolecular and surface forces. 3rd ed. Amsterdam: Academic Press; 2011.

Jin H, Wang W, Chang H, et al. Effects of salt-controlled self-assembly of triblock copolymers F68 on interaction forces between oil drops in aqueous solution. Langmuir. 2017;33(51):14548-555. https:// doi.org/10.1021/acs.langmuir.7b02925.

Jin H, Wang W, Yu Z, et al. Experimental study of the salinity-specific adhesion force between oil drop and underwater superoleophobic polyelectrolyte surfaces. ACS Appl Polym Mater. 2019;1(10):2582-9. https://doi.org/10.1021/acsapm.9b00331.

Jurin FE, Buron CC, Martin N, et al. Electrical conductivity enhancement and wettability modification of (PDDA/PEDOT: PSS)n multilayer film. Thin Solid Films. 2018;664:33-40. https://doi. org/10.1016/j.tsf.2018.07.044.

Kobayashi M, Terayama Y, Yamaguchi H, et al. Wettability and antifouling behavior on the surfaces of superhydrophilic polymer brushes. Langmuir. 2012;28(18):7212-22. https://doi. org/10.1021/la301033h. 
Kristiansen K, Stock P, Baimpos T, et al. Influence of molecular dipole orientations on long-range exponential interaction forces at hydrophobic contacts in aqueous solutions. ACS Nano. 2014;8(10):10870-7. https://doi.org/10.1021/nn504687b.

Liao M, Cheng G, Zhou J. Underwater superoleophobicity of pseudozwitterionic SAMs: effects of chain length and ionic strength. J Phys Chem C. 2017;121(32):17390-401. https://doi.org/10.1021/ acs.jpcc.7b06088.

Liu X, Leng C, Yu L, He K, et al. Ion-specific oil repellency of polyelectrolyte multilayers in water: molecular insights into the hydrophilicity of charged surfaces. Angew Chem Int Ed. 2015;54(16):4851-6. https://doi.org/10.1002/anie.201411992.

Luo L, Nie G, Tian D, et al. Dynamic self-assembly adhesion of a paraquat droplet on a pillar arene surface. Angew Chem Int Ed. 2016;55(41):12713-6. https://doi.org/10.1002/anie.201603906.

Ma CD, Wang C, Acevedo-Velez C, et al. Modulation of Hydrophobic interactions by proximally immobilized ions. Nature. 2015;517:347-50. https://doi.org/10.1038/nature14018.

Malotky DL, Chaudhury MK. Investigation of capillary forces using atomic force microscopy. Langmuir. 2001;17(25):7823-9. https ://doi.org/10.1021/la0107796.

Mate CM, Lorenz MR, Novotny VJ. Atomic force microscopy of polymeric liquid films. J Chem Phys. 1989;90:7550-5. https://doi. org/10.1063/1.456188.

Mettu S, Berry JD, Dagastine RR. Charge and film drainage of colliding oil drops coated with the nonionic surfactant $\mathrm{C}_{12} \mathrm{E}_{5}$. Langmuir. 2017;33(20):4913-23. https://doi.org/10.1021/acs.langmuir.6b046 32.

Rasitha TP, Vanithakumari SC, George RP, et al. Template-free onestep electrodeposition method for fabrication of robust superhydrophobic coating on ferritic steel with selfcleaning ability and superior corrosion resistance. Langmuir. 2019;35(39):12665-79. https://doi.org/10.1021/acs.langmuir.9b02045.

Rios-Carvajal T, Pedersen NR, Bovet N, et al. Specific ion effects on the interaction of hydrophobic and hydrophilic self-assembled monolayers. Langmuir. 2018;34(35):10254-61. https://doi. org/10.1021/acs.langmuir.8b01720.

Rostami P, Sharifi M, Aminshahidy B, et al. The effect of nanoparticles on wettability alteration for enhanced oil recovery: micromodel experimental studies and CFD simulation. Pet Sci. 2019;16(4):859-73. https://doi.org/10.1007/s12182-019-0312-z.

Shi C, Cui X, Xie L, et al. Measuring forces and spatiotemporal evolution of thin water films between an air bubble and solid surfaces of different hydrophobicity. ACS Nano. 2015;9(1):95-104. https ://doi.org/10.1021/nn506601j.

Shi C, Yan B, Xie L, et al. Long-range hydrophilic attraction between water and polyelectrolyte surfaces in oil. Angew Chem Int Ed. 2016;55(48):15017-21. https://doi.org/10.1002/anie.201608219.

Shi C, Zhang L, Xie L, et al. Surface interaction of water-in-oil emulsion droplets with interfacially active asphaltenes. Langmuir. 2017;33(5):1265-74. https://doi.org/10.1021/acs.langmuir.6b042 65.

Snyder BA, Aston DE, Berg JC. Particle-drop interactions examined with an atomic force microscope. Langmuir. 1997;13(3):590-3. https://doi.org/10.1021/la960903z.

Song $\mathrm{M}, \mathrm{Hu} \mathrm{D}$, Zheng $\mathrm{X}$, et al. Enhancing droplet deposition on wired and curved superhydrophobic leaves. ACS Nano. 2019;13(7):7966-74. https://doi.org/10.1021/acsnano.9b02457.

Su B, Li M, Shi Z, et al. From superhydrophilic to superhydrophobic: controlling wettability of hydroxide zinc carbonate film on zinc plates. Langmuir. 2019;25(6):3640-5. https://doi.org/10.1021/ la803948m.

Sudha US, George RP, Vishwakarma V, et al. Enhanced seawater corrosion resistance of reinforcement in nanophase modified fly ash concrete. Constr Build Mater. 2019;221:232-43. https://doi. org/10.1016/j.conbuildmat.2019.06.070.
Tabor RF, Manica R, Chan DYC, et al. Repulsive van der Waals forces in soft matter: why bubbles do not stick to walls. Phys Rev Lett. 2011a;106(6):064501. https://doi.org/10.1103/PhysRevLet t.106.064501.

Tabor RF, Wu C, Lockie H, et al. Homo- and hetero-interactions between air bubbles and oil droplets measured by atomic force microscopy. Soft Matter. 2011b;7(19):8977-83. https://doi. org/10.1039/C1SM06006F.

Tabor RF, Morfa AJ, Grieser F, et al. Effect of gold oxide in measurement s of colloidal force. Langmuir. 2011c;27(10):6026-30. https ://doi.org/10.1021/la200166r.

Tabor RT, Wu C, Grieser F, et al. Non-linear and cyclical collisions between drops and bubbles: using AFM to understand droplet interactions in micro-scale flows. Soft Matter. 2013;9(8):2426-33. https://doi.org/10.1039/C2SM27463A.

Tang Y, Zhang X, Choi P, et al. Underwater adhesion of a stimuliresponsive polymer on highly oriented pyrolytic graphite: a single-molecule force study. J Phys Chem C. 2018a;122(12):6721-9. https://doi.org/10.1021/acs.jpcc.8b00359.

Tang Y, Zhang X, Choi P, et al. Contributions of van der Waals interactions and hydrophobic attraction to molecular adhesions on a hydrophobic $\mathrm{MoS}_{2}$ surface in water. Langmuir. 2018b;34(47):14196-203. https://doi.org/10.1021/acs.langm uir.8b02636.

Teng X, Yu C, Wu X, et al. PTFE/SPEEK/PDDA/PSS composite membrane for vanadium redox flow battery application. J Mater Sci. 2008;53(7):5204-15. https://doi.org/10.1007/s10853-017-1903-y.

Vakarelski IU, Dagastine RR, Chan DYC, et al. Lateral hydrodynamic interactions between an emulsion droplet and a flat surface evaluated by frictional force microscopy. Langmuir. 2010a;26(11):8002-7. https://doi.org/10.1021/la904894n.

Vakarelski IU, Manica R, Tang X, et al. Dynamic interactions between microbubbles in water. PNAS. 2010b;107(25):11177-82. https:// doi.org/10.1073/pnas.1005937107.

Wang Y, Wang S, Xiao M, et al. Layer-by-layer self-assembly of PDDA/PSS-SPFEK composite membrane with low vanadium permeability for vanadium redox flow battery. RSC Adv. 2013;3(35):15467-74. https://doi.org/10.1039/C3RA41670D.

Wang W, Li K, Ma M, et al. Review and perspectives of AFM application on the study of deformable drop/bubble interactions. Adv Colloid Interface Sci. 2015;225:88-97. https://doi.org/10.1016/j. cis.2015.08.005.

Xie L, Shi C, Cui X, et al. Surface forces and interaction mechanisms of emulsion drops and gas bubbles in complex fluids. Langmuir. 2017a;33(16):3911-25. https://doi.org/10.1021/acs.langm uir.6b04669.

Xie L, Wang J, Yuan D, et al. Interaction mechanisms between air bubble and molybdenite surface: impact of solution salinity and polymer adsorption. Langmuir. 2017b;33(9):2353-61. https://doi. org/10.1021/acs.langmuir.6b04611.

Young T. An essay on the cohesion of fluids. Philos Trans R Soc. 1805;95:65-87. https://doi.org/10.1098/rstl.1805.0005.

Zaibudeen AW, Philip J. Behavior of a strong polyelectrolyte, poly(diallyldimethylammonium chloride) physisorbed at oilwater interface under different environments: a comparison with a weak polyelectrolyte. Colloids Surf A Physicochem Eng Asp. 2018;550:209-21. https://doi.org/10.1016/j.colsurfa.2018.04.052.

Zerball M, Laschewsky A, Klitzing R. Swelling of polyelectrolyte multilayers: the relation between, surface and bulk characteristics. J Phys Chem B. 2015;119(35):11879-86. https://doi.org/10.1021/ acs.jpcb.5b04350.

Zhang P, Zhang F, Zhao C, et al. Superspreading on immersed gel surfaces for the confined synthesis of thin polymer films. Angew Chem Int Ed. 2016a;55(11):3615-9. https://doi.org/10.1002/ anie. 201510291. 
Zhang X, Tchoukov P, Manica R, et al. Simultaneous measurement of dynamic force and spatial thin film thickness between deformable and solid surfaces by integrated thin liquid film force apparatus. Soft Matter. 2016b;12(44):9105-14. https://doi.org/10.1039/ C6SM02067D.
Zheng Y, Bai H, Huang Z, et al. Directional water collection on wetted spider silk. Nature. 2010;463:640-3. https://doi.org/10.1038/ nature 08729. 